This item was submitted to Loughborough's Research Repository by the author.

Items in Figshare are protected by copyright, with all rights reserved, unless otherwise indicated.

\title{
On optimising risk exposures with trend-following strategies in currency overlay portfolios
}

\section{PLEASE CITE THE PUBLISHED VERSION}

http://dx.doi.org/10.21314/JOIS.2016.078

\section{PUBLISHER}

Incisive Risk Information Limited

\section{VERSION}

AM (Accepted Manuscript)

\section{PUBLISHER STATEMENT}

This work is made available according to the conditions of the Creative Commons Attribution-NonCommercialNoDerivatives 4.0 International (CC BY-NC-ND 4.0) licence. Full details of this licence are available at: https://creativecommons.org/licenses/by-nc-nd/4.0/

\section{LICENCE}

CC BY-NC-ND 4.0

\section{REPOSITORY RECORD}

Tee, Kai-Hong. 2019. "On Optimising Risk Exposures with Trend-following Strategies in Currency Overlay Portfolios”. figshare. https://hdl.handle.net/2134/23194. 


\title{
On Optimising Risk Exposures with Trend-Following Strategies in \\ Currency Overlay Portfolios
}

\author{
Kai-Hong Tee*
}

\begin{abstract}
This paper proposed an optimisation mechanism in the currency overlay portfolios construction process, an area that has not been explored in the literature that tend to focus on pre-determined fixed weights, such as the trading volume of currencies from the survey of the Bank for International Settlement, to construct overlay portfolios and may not always be optimal. This paper optimises the portfolio using the Cholesky Decomposition-based multivariate TVC (Time varying correlation)-GARCH and CC (Constant correlation) GARCH models as allocation schemes, with underlying currencies’ returns originated from a moving average-based trend following single FX strategy in a certain hedging criterion. This paper includes a FX strategy based on the equally weighted (average) of the three different single moving average days to determine hedging needs underlying the hedging criterion. The paper uses the returns of the strategies of EW (equally weighted)-TFX and TFX to construct the optimal currencies overlay portfolios. The findings reveal the EW-TFX portfolios with the TVC-GARCH scheme have the best risk-adjusted portfolio returns. There are some evidences on the significant differences of the portfolios' returns of the EW-TFX overlay portfolios with other currencies portfolios, hence supporting the outperformance. The findings also support existing evidence in the literature.
\end{abstract}

\section{JEL: G1; F3; C1; C5.}

Keywords: Currency overlay portfolios, time-varying correlation (TVC)-GARCH model, hedging criterion, trend following strategy, Cholesky Decomposition.

\footnotetext{
* Loughborough University, School of Business and Economics, United Kingdom. Email: k.tee@lboro.ac.uk
} 


\section{Introduction}

The triennial survey by the Bank for International Settlement (BIS) consistently reported trading volumes of the currency markets to be on the rise, with a recent survey showing that trading volume soared to over $\$ 4$ trillion a day --- a $20 \%$ gain in the global foreign exchange markets from \$3.3 trillion in 2007. With the rise of globalization and electronic trading, non-bank players such as hedge funds have emerged as major players in the currency market with their shares of daily volume matching the interbank as of 2007 (Gallardo and Heath, 2009). These 'non-bank' players in the currency market based on observations by Nasypbek and Rehman (2011), not only consist of different types of investment funds managers, from hedge funds to mutual funds, which are increasingly using the currency markets as a distinct asset class, but also currency overlay firms, which traditionally serviced clients who prefer passive hedging and also view currency as an asset class, with an aim to generate profits from buying and selling currencies, independent of any other activity such as hedging, market-making, or trading equity and bond securities.

The survey from the BIS shows that researching on the currency overlay portfolio is of a tropical interest and relevant, especially on their performances and this is the main aim of the paper. Additionally, this paper proposes an optimisation mechanism in the process of currency overlay portfolios construction, an area that has not been explored in the literature that often uses pre-determined fixed weights, such as the trading volume of currencies from the BIS survey, to construct currency overlay portfolios and this may not be optimal. The findings in this paper reveal that conditionally hedging the currency exposure could produce better risk-adjusted returns that minimise the FX exposure, if applying the appropriate allocation scheme and this provides support to the evidence in the existing literature. In the 
next section, I survey the related literatures to support the needs for the optimisation of the FX exposures. Then, I discuss the suggested methodology for this paper and followed by the discussion of the findings and finally I conclude the paper.

\section{Literature Review}

The use of Active Currency Management activities has increasingly gained attention over the past years following market globalisation that prompted increased allocations to international assets. Pojarliev and Levich (2012) suggest that the realization that the currency component of an international portfolio might be actively hedged, and profitably so, had led some managers to offer currency management as a separate product. Other currency management mandates, according to Pojarliev and Levich, include the absolute return and currency overlay mandates. Research on currency overlay management in the literature dates back as early as Solnik (1997). LaBarge (2010) lists out what Solnik (1997) commented on currency overlay management. Solnik (1997) commented that investors can adopt a separate currency overlay strategy. In this case, there are two basic ways to separately manage the currency exposure that arises from holding a portfolio of international securities: partial optimisation and separate optimisation. The 'partial optimisation' is where the currency overlay is the second step in the asset management process, after determining the asset allocation for the portfolio, while in the 'separate optimisation', the currency overlay is a standalone mandate, and neither the overlay manager nor the asset manager has knowledge of the other's activities. The overlay manager may or may not be given the discretion to decide the optimal currency weights. An integrated approach was also introduced in Jorion (1994), where the optimal weights of both the underlying securities and the currencies are determined simultaneously. 
Existing academic literatures on the research of currency overly portfolio is not very clear on which mandate they are following. Their approaches are mostly focused on the underlying currency strategies that aim at maximising the returns from managing the FX exposures. This has the advantage of highlighting the significance of currency overlay in contributing to the overall returns and performance of the international portfolios for investors. A distinguishing feature of this paper is to make contribution not just in highlighting the FX/currency overlay strategy, but also to optimise the returns of the FX strategies to construct currency overlay portfolios.

The earlier literature shows Acar and Lequeux (2001) to be the main research in the area of currency overlay strategy. They comment that while managing actively the currency exposure will not necessarily produce incremental returns, this often al so does not imply that active strategies would not reduce risk $^{1}$. Existing literature follows the similar line of enquiries that Acar and Lequeux (2001) took to explore the effectiveness of currency overlay program and this includes Dunis and Levy (2002), Tee (2009) and Pojarliev (2005). The results in Dunis and Levy (2002) indicate that the use of an overlay program to manage currency exposures adds to the risk-adjusted returns of the portfolios. In particular the use of “exotic currencies” is proven to add superior risk-adjusted returns before and even after the addition of transaction costs, compared to an overlay of only "major currency" paired to the U.S dollar. Their findings demonstrate a further benefit of international diversification to emerging markets, in association to the use of emerging markets' currencies, which they termed as “exotic currencies”. Pojarliev (2005) considers both trend following and carry trade strategies on emerging and developed currencies, where findings reveal trend-following rules to work better for emerging market currencies. Tee (2009) reveals research findings showing

\footnotetext{
${ }^{1}$ Appendix 1 of their paper discusses the stochastic properties of the dynamic strategies implemented in their currency overlay program, aiming at risk reduction
} 
using active currency management was beneficial to an international equity portfolio for Japanese investors who include hedge funds as part of their equity portfolios, as compared to those who did the same from the Euro-zones, Swiss and the UK. These findings reaffirm the role of effective currency management via an overlay program or simply actively managing currency exposure in international assets portfolios.

Lindahl (1997) observes different currency (FX) trading strategies underlying the currency overlay programs. What implemented in Acar and Lequexux (2001) can be classified as a FX momentum strategy, which was followed by Dunis and Levy (2002), Tee (2009) and Pojarliev (2005). More recent literature expands the scope of FX strategies to include the FX carry trade, the FX momentum, and the FX value strategy as discussed in Kroenche et al (2014), who study the diversification benefits of these three FX investment styles, as evidence provided in Middleton (2005) reveals that currency overlay managers could adopt a few as well as single FX investment style(s). Consistent with this observation, the aim of this paper is to investigate the diversification effects underlying the currency overlay portfolios that adopt single FX momentum strategy (style). The style is based on a technical trend following rule that largely uses moving average as trading signals.

Acar and Lequeux (2001) explain that, due to the highly likely serial dependence, which violates some assumptions underlying traditional optimization techniques, and renders these optimization results to be flawed, currency overlay managers have been adding values to portfolios that include foreign assets by following a rule whereby they vary their currency exposures in accordance with trend-following rule. The "Buy" and "Sell" signals generated by moving averages could be used to dynamically hedge the currency component of international assets. For instance, a German investor having invested in the United States 
might use the "Buy" signal generated on Euro futures contract to repatriate the dollar investment into Euro. When a "Sell" signal is generated the German investor will keep or regain his unhedged position that is implicitly short of euro. The reciprocal case involves an American investor having bought some German assets. He will use the "Sell" signal generated on euro futures contract to repatriate the euro investment into dollars. Likewise, he will keep or regain his unhedged position that is implicitly short of dollars. This strategy uses trend following based technical trading rule applying moving average to detect the strength of the price movement of exchange rates to execute the "buy" or "sell" decision.

While existing literature that follow Acar and Lequeux (2001) have often shown that currency overlay portfolios perform better than using hedging or no hedging style of currency managements, these literature, however, often simplify the multi-currencies (overlay) portfolios construction by assuming equally weighted scheme (Pojarliev, 2005) or the BIS surveyed FX trading volume (Acar and Lequeux, 2001). Such allocation of the currencies' weights could lead to sub-optimal outcomes and also pointed out in Dunis and Levy (2002). However, the caution of s "sub-optimal" outcome has not prevented subsequent researches to treat the allocation differently. Gyntelberg and Schrimpf (2012), for example, show that short-term multi-currencies investment that use strategies (i.e., carry-trade, momentum and term-spread strategies) which are equally weighted, reveal evidence of downside risk properties during periods of financial distress. They show that the strategies exhibit substantial tail risks and also do not appear to perform uniformly during periods of turmoil in global markets. Their research also reveals that the common equity benchmarks feature even greater downside risks than those foreign exchange investment strategies. This prompted the need to re-think the issue of allocation mechanism of multi-currencies portfolio within a currency overlay program, as they will impact on risk and diversification effects. This also 
grows in importance in volatile markets condition such as the periods of the financial crisis in 2008 or the more recent post Brexit period in 2016. I propose in this paper allocation mechanisms for multi-currencies portfolios underlying returns originated from single FX strategy style. The next section discusses the methodology, and should follow by the discussion of data and findings, and then the conclusion of the paper.

\section{Trend-following FX strategy and Allocation methodology}

\subsection{Trend-following FX strategy, Data and Time period}

The academic literature focuses on the risk reduction potential of currency overlay programs. More recent studies in this area investigate the portfolios' returns outcomes in terms of skewness and consider the combination of FX strategies. For example, Kroencke et al (2014) provide a comprehensive analysis of portfolio choice with three widely practiced FX investment styles. They use the well-known carry trades and also investigate the FX momentum and FX value strategies. Using currencies from 30 countries from 1976 to 2011, they conduct research to test the viability of the chosen FX strategies underlying the currency overlay portfolios. This was benchmarked against alternative hedging strategies that include the full hedge, optimal hedge and conditional optimal hedge versions, drawing on the work by Campbell, et, al (2010). Two of their research findings include, firstly, showing considerable improvements in the portfolio allocation can be achieved by style investing in the currency markets. Considering all the three currency strategy styles increases the (annualized) Sharpe ratio from 1.25 (benchmark assets, conditional optimal hedge) to 1.62 (FX style augmented portfolio), an increase of about 30\%. Secondly, they show that the combination of all the three currency strategies improves the portfolio allocations more than 
relying on a single currency style in isolation. As correlations among these three strategies are fairly low, diversification benefits were therefore expected. The portfolio outcomes turn out to be much less exposed to negative skewness, implying the reduction in the exposure to potential downside risks.

Different to Kroencke et al (2014) and Gyntelberg and Schrimpf (2012), this paper focuses on a single FX strategy style underlying a momentum-based trend following approach in the currency overlay portfolios as discussed in the literature. The momentumbased approach is similar to those in Kroencke, et al (2014), except that they use different variables. Their momentum portfolio goes long in a portfolio of currencies with the highest past cumulative returns (so-called "winners") and short in a portfolio of currencies with the lowest past returns (so-called "losers"). They based the conditioning variable of the momentum strategy on the cumulative return over the past three months, which was later used as a signal for hedging or non-hedging position on a particular currency. Instead of classifying the currencies as winners or losers groups, this paper directly computes moving averages' days of 32, 61 and 117 to assess the strength and pattern of the currencies' movements, and later used to signal for hedging or no hedging decision. The moving averages of 32, 61 and 117 days were used in Acar and Lequeux (2001) and widely applied in the literature, such as Tee (2009) and Dunis \& Levy (2002). 


\section{Figure 1: The Execution of the FX strategy underlying the hedging criterion}

\section{The TFX strategy}

Step 1: Compute the moving averages of 32, 61 and 117 days using daily spot rates for each of the currencies of GBP, JPY and EURO, all against the USD

Step 2: For each currency, compare each of the three individual-moving-average days' (i.e., 32, 61 and 117 days) averages with the actual weekly spot rate on the same week date.

Step 3: If the actual weekly spot rate is more than any two of the three individual-movingaverage days' averages on the same week date, then apply $50 \%$ hedge. If it is less than any two of the three individual-moving-average days' averages on the same week date, then unhedge the position.

Step 4: Compute weekly returns based on the hedge or un-hedge position, by comparing with either the forward or spot rate recommended from the hedging criterion in the previous week.

\section{The EW-TFX strategy}

Step 1: Compute the moving averages of 32, 61 and 117 days using daily spot rates for each of the currencies of GBP, JPY and EURO, all against the USD

Step 2: For each currency, compare the average of the three individual-moving-averages with the actual weekly spot rate on the same week date.

Step 3: If the actual weekly spot rate is more than the average of the three individual-movingaverages, then apply 50\% hedge. If it is less than the average of the three individual-movingaverages on the same week date, then un-hedge the position

Step 4: Compute weekly returns based on the hedge or un-hedge position, by comparing with either the forward or spot rate recommended from the hedging criterion in the previous week 
The criterion for hedging decision incorporates a trend-following FX strategy which has also been applied in the literature. Figure 1 describes the steps to execute the strategy following the hedging criterion. The steps involve firstly computing the moving averages of 32, 61 and 117 days using daily spot rates for each of the currencies of GBP, JPY and EURO, all against the USD. Then, a hedging rule is employed. This requires comparing each of the three individual-moving-average days' averages with the actual weekly spot rate on the same week date. If the actual weekly spot rate is more than any two of the three individual-movingaverage days' averages on the same week date, then apply $50 \%$ hedge. If it is less than any two of the three individual-moving-average days on the same week date, then the position is un-hedged. Then, I compute weekly FX returns based on the hedge or un-hedge position, by comparing with either the forward or spot rate as appropriate, which may or may not change following one week to the next, depending on the recommendation from the hedging criterion. I defined this as the TFX strategy.

On the other hand, I also compare the average of the three individual-movingaverages (i.e., 31, 62 and 117 days) with the actual weekly spot rate on the same week date. If the actual weekly spot rate is more than the average of the three individual-moving-averages, then I apply 50\% hedge. If it is less than the average of the three individual-moving-averages on the same week date, then I un-hedged the position. I defined this as the EW-TFX strategy. This trend following FX strategy together with the hedging criterion has been shown in Dunis and Levy (2002) and Leqeuex and Acar (2001) to result in better risk reduction for the currency overlay portfolios. 
All the currencies used in this paper are obtained from the Datastream, Inc. and they are the GBP/USD, JPY/USD and EUR/USD. These are some of the most heavily traded currencies based on the latest BIS survey (2016). They also belong to countries where capital markets and financial investments are the more developed and constantly attract capital flows. The period of study ranges from 1998 to 2010 and use a weekly and daily forward contract and spot rates. The daily currencies spot rates are used to estimate moving averages of 32, 61 and 117 days, and then they are compared with the actual weekly spot rates to decide if hedging or no hedging is required, where a weekly holding period will follow thereafter (and assuming a hedging period of one week should hedging be recommended, and therefore a weekly forward rate would apply) and then a weekly return computed.

The weekly returns computed are based on the hedge or un-hedge position, by comparing with either the forward or spot rate recommended from the hedging criterion in the previous week. The weekly FX strategies' (both TFX and EW-TFX) returns' computations starts from the first week of 1999, based on the moving averages back dated to the last week of 1998. The FX strategies’ returns are computed on a rolling window basis one week to the next following the hedging criterion until the last week of 2010. This paper studies the management of the FX exposure in currency overlay programs supporting foreign assets’ investments. It also applies to different allocation schemes on the various currencies portfolios of different exposure management styles, including the TFX and EW-TFX currency overlay portfolios ${ }^{2}$.

\footnotetext{
2 The portfolios' outcome, measured in USD currency, is the incremental value the management of the FX exposure delivers to the US investors holding foreign assets' in their portfolios. The effects of the foreign assets' investments, however, are not discussed in this paper.
} 
Table 1: Descriptive Statistics of currencies* from the three currency management methods

\begin{tabular}{|c|c|c|c|c|c|c|c|c|c|c|c|c|}
\hline & \multicolumn{3}{|c|}{ Hedged } & \multicolumn{3}{|c|}{ Unhedged } & \multicolumn{3}{|c|}{ TFX } & \multicolumn{3}{|c|}{ EW-TFX } \\
\hline & JPY & GBP & EURO & JPY & GBP & EURO & JPY & GBP & EURO & JPY & GBP & EURO \\
\hline Mean & $0.0513 \%$ & $-0.0124 \%$ & $0.0196 \%$ & $0.0527 \%$ & $-0.0117 \%$ & $0.0197 \%$ & $0.0530 \%$ & $-0.0110 \%$ & $0.0169 \%$ & $0.0542 \%$ & $-0.0110 \%$ & $0.0168 \%$ \\
\hline Median & $0.0048 \%$ & $0.0823 \%$ & $0.0162 \%$ & $-0.0415 \%$ & $0.0735 \%$ & $0.0203 \%$ & $0.0029 \%$ & $0.0191 \%$ & $0.0471 \%$ & $0.0070 \%$ & $0.0200 \%$ & $0.0471 \%$ \\
\hline Maximum & $4.9170 \%$ & $5.5495 \%$ & $9.0161 \%$ & $5.6020 \%$ & $4.3612 \%$ & $9.0102 \%$ & $6.5498 \%$ & $4.7245 \%$ & $9.8089 \%$ & $6.1804 \%$ & $4.7245 \%$ & $9.8089 \%$ \\
\hline Minimum & $-4.8102 \%$ & $-7.0524 \%$ & $-6.0837 \%$ & $-4.6217 \%$ & $-6.0655 \%$ & $-6.0853 \%$ & $-3.9667 \%$ & $-6.7262 \%$ & $-5.0939 \%$ & $-3.9927 \%$ & $-6.7262 \%$ & $-5.0939 \%$ \\
\hline Std. Dev. & $1.3885 \%$ & $1.3647 \%$ & $1.4516 \%$ & $1.4012 \%$ & $1.3182 \%$ & $1.4517 \%$ & $1.3924 \%$ & $1.3087 \%$ & $1.4655 \%$ & $1.3953 \%$ & $1.3087 \%$ & $1.4650 \%$ \\
\hline Skewness & 0.186075 & -0.485765 & 0.278799 & 0.278547 & -0.523413 & 0.277959 & 0.470191 & -0.500914 & 0.298722 & 0.426254 & -0.505213 & 0.298049 \\
\hline Kurtosis & 3.701445 & 6.012978 & 6.103539 & 3.717931 & 4.931746 & 6.096603 & 4.47362 & 5.249094 & 5.966741 & 4.054901 & 5.236457 & 5.972718 \\
\hline $\begin{array}{c}\text { Jarque- } \\
\text { Bera }\end{array}$ & 16.44608 & 261.4047 & 259.3432 & 21.53904 & 125.917 & 258.1727 & 79.70738 & 158.1194 & 238.884 & 47.98247 & 157.0921 & 239.768 \\
\hline Probability & 0.000268 & 0 & 0 & 0.000021 & 0 & 0 & 0 & 0 & 0 & 0 & 0 & 0 \\
\hline & & & & & & & & & & & & \\
\hline
\end{tabular}

Note: JPY, GBP and Euro are the currencies of Japanese, British Pound and Euro. These are reported in US dollar terms. Hedged, Unhedged, TFX and EWTFX signify different currency managements. Hedged and unhedged currencies use forward contracts and spot rates respectively. TFX and EW-TFX are based on hedging criterions. TFX uses the three individual moving averages of 32, 61 and 117 days to determine hedging needs. EW-TFX uses equallyweighted value of the three moving average days of 32, 61 and 117 to determine hedging needs. See figure 1 on the steps involved to execute the two trend following FX strategies. 
Table 1 presents the summary statistics for the three currencies and their hedged, unhedged, TFX and EW-TFX returns. Recent literature such as Gyntelberg and Schrimpf (2012) reveal that individual FX strategy such as the carry trade and momentum strategies exhibit clear asymmetric risks patterns, implying the prevalence of downside risks. This brought us to question what extent could exposures be further reduced when these strategies are used in a currency overlay portfolio. On the basis of a single FX strategy, this paper shows in table 1 that significant skewness is present in the individual currency, which implies potential serial correlation/dependence with the likelihood of returns clustering on the downside or upside. This shows the FX strategies' returns can be modelled using the conditional volatility assumption and applied in the optimisation process and to construct the currency overlay portfolios. The next section discusses the modelling technique.

\subsection{TVC-GARCH Model as allocation methodology for currencies overlay portfolios}

This section discusses the technique to optimise the currencies' returns associated with the TFX and EW-TFX strategies discussed in section 3.1. This paper models the timevarying correlation in a Multivariate GARCH model based on Tsay (2005). Tsay (2005) reparameterizes the variance-covariance matrix of the multivariate GARCH model using the Cholesky decomposition resulting in this approach requiring no parameter constraints for the positive definiteness of the variance-covariance matrix (see Pourahmadi (1999)), which is advantageous when involving more than two variables in the model. The Cholesky Decomposition and orthogonal transformation re-parameterize the conditional variance and covariance functions ${ }^{3}$, and the correlation coefficient listed as below:

\footnotetext{
${ }^{3}$ see appendix 1 which illustrates the Cholesky decomposition and the derivations of the conditional variance and covariance functions, and the estimation models of the parameters under the matrix inversion transformation found in Tsay (2005)
} 


$$
\rho_{i j, t}=\frac{\sigma_{i j, t}}{\sqrt{\sigma_{i i, t} \sigma_{j j, t}}}=q_{21, t} \times \frac{\sqrt{\sigma_{11, t}}}{\sqrt{\sigma_{22, t}}}
$$

which is time-varying if $q_{21, t}$ is not 0 and if $\frac{\sqrt{\sigma_{11, t}}}{\sqrt{\sigma_{22, t}}}$ is not a constant ${ }^{4}$. Redefining the correlation coefficient based on the re-parameterisations of conditional variances $\left(\sigma_{i i, t} \sigma_{j j, t}\right)$ and conditional covariance $\left(\sigma_{i j, t}\right)$ transformed the above function as follows (Asai, et al (2006)):

$$
\rho_{i j, t}=\frac{\sigma_{i j, t}}{\sqrt{\sigma_{i i, t} \sigma_{j j, t}}}=\frac{\sum_{v=1}^{j} q_{i v, t} q_{j v, t} \mathrm{~g}_{v v, t}}{\sqrt{\sum_{v=1}^{i} q_{i v, t}^{2} \mathrm{~g}_{v v, t} \sum_{v=1}^{j} q_{j v, t}^{2} \mathrm{~g}_{v v, t}}}
$$

From above, it becomes clear that the driving forces underlying the time varying correlations are dependent upon the dynamics of the $g_{i i}$ and $q_{i j}$ parameters ${ }^{5}$. The reparameterization has interesting implications on the correlation coefficients. Correlation underlies the interdependence between two markets' returns assumes a linear relationship. This assumption is often retained in existing Multivariate-GARCH models within conditional covariance functions. The extent of impact it imposes varies, depending on whether correlations are modelled as a constant or a time-varying variable. One such example is the DCC (Dynamic Conditional Correlation) multivariate GARCH model introduced in Engle (2002). Existing literature such as Jondeau and Rockinger (2001) rely on modelling dependence structure of assets' returns (within Multivariate GARCH model) facing this assumption. The re-parameterisation of the correlation under Cholesky Decomposition in Multivariate GARCH framework of Tsay (2005), however, implicitly reduces the effects of correlation coefficient, known to be a strictly linear market interdependent measure.

\footnotetext{
${ }^{4}$ The parameter $q_{21, t}$ is used in the Cholesky decomposition process. Appendix 1 illustrates this.

${ }^{5}$ The $g_{i i}$ and $q_{i j}$ parameters as defined in (5) are the generalisations forms as derived in $\sum_{t}$ illustrated in Appendix 1.
} 
The effectiveness of the correlation as a linear interdependence measure could be assessed by testing if the underlying pairs of markets' returns follow a bivariate normality distribution as discussed in Embrechts et al (1999). I adopt the Mardia bivariate normality test, where results show the null hypotheses of bivariate normality among the currencies pairs of Euro, Sterling pounds and Japanese Yen are all rejected for the entire estimation periods from 1999 to 2010, implying that assets' bivariate distributions are nonlinear ${ }^{6}$. This follows that the market interdependence implied by correlation may not reveal the true interdependence patterns of the assets' pairs. Including them as inputs when allocating assets may not necessarily be appropriate and could lead to suboptimal outcomes.

To assess the effects of correlations, this paper compares portfolio performance of TVC-GARCH $(1,1)$ with Constant Correlation (CC)-GARCH(1,1) model introduced in Bollerslev (1990), where correlations are modelled as a constant throughout the estimation periods. The conditional covariance model of the CC-GARCH $(1,1)$ model defined as follows:

$$
H_{t}=D_{t} \boldsymbol{R} D_{t}=\left(\rho_{i j} \sqrt{h_{i i t} h_{j j t}}\right)
$$

Where $D_{t}=\operatorname{diag}\left(h_{11 t}^{\frac{1}{2}} \ldots . h_{N N t}^{\frac{1}{2}}\right)$ and $h_{\text {iit }}$ is defined as any univariate GARCH model and $\boldsymbol{R}=\left(\rho_{i j}\right)$ is a matrix containing the constant correlation coefficient and is a symmetric positive definite matrix with $\rho_{i i}=1, \forall i$

\footnotetext{
${ }^{6}$ See appendix 2 for the discussion of the Mardia bivariate normality test
} 
I construct two currency overlay portfolios based on the optimisation of the returns of the TFX and EW-TFX strategies ${ }^{7}$. The optimisations use TVC-GARCH $(1,1)$ and CCGARCH $(1,1)$ as allocation schemes. To compare the effect on the allocation, this paper includes the Markowitz allocation model and to compare the effect on the type of currency risk managements, a fully hedged and unhedged (i.e., spot rate) currencies portfolios are also optimally constructed, based on the various allocation schemes. Proportional weights are derived via the optimisations in-sample using the recursive window approach, where the initial estimation date is fixed on the first week of January of 1999 until the last week of December in 2009 to derive weights to form portfolios in the one-week ahead period for January 2010 and additional observations added one at a time to the estimation period with the last dated from the first week of January 1999 until the third week of December in 2010 to derive weights to form portfolios out sample for December 2010. The next section discusses the findings.

\section{Discussion of findings}

\subsection{Correlations, allocation weights and currencies portfolios performance}

Table 2 shows the descriptive statistics of the out sample weekly portfolios returns from January 2010 to December 2010. Overall, the TVC-GARCH (TVC) allocation scheme provides better returns for the EW-TFX and TFX overlay portfolios than the hedged and unhedged currencies portfolios. This applies to other allocation schemes as observed from the table. The returns are also relatively better for the average weekly and the median returns for the overlay portfolios, with the EW-TFX overlay portfolios better than the TFX overlay

\footnotetext{
${ }^{7}$ See figure 1 on the execution of the strategies
} 
Table 2: Comparison of the full out sample currencies portfolio returns under each allocation scheme

\begin{tabular}{|c|c|c|c|c|}
\hline Markowitz (MV) & Hedged & Unhedged & EW-TFX & TFX \\
\hline Average weekly return* & $0.055 \%$ & $0.048 \%$ & $0.058 \%$ & $0.050 \%$ \\
\hline Median return & $-0.069 \%$ & $-0.058 \%$ & $-0.006 \%$ & $-0.046 \%$ \\
\hline Max & $2.121 \%$ & $2.220 \%$ & $1.649 \%$ & $2.223 \%$ \\
\hline Min & $-2.345 \%$ & $-2.594 \%$ & $-2.625 \%$ & $-2.590 \%$ \\
\hline Standard Deviation (SD) & $0.942 \%$ & $0.991 \%$ & $0.887 \%$ & $0.991 \%$ \\
\hline $\begin{array}{l}\text { Risk-adjusted return } \\
\text { (mean-SD ratio) }\end{array}$ & 0.058 & 0.048 & 0.065 & 0.051 \\
\hline CC-GARCH(1,1) (CC) & Hedged & Unhedged & EW-TFX & TFX \\
\hline Average weekly return* & $0.045 \%$ & $0.036 \%$ & $0.087 \%$ & $0.064 \%$ \\
\hline Median return & $-0.085 \%$ & $0.027 \%$ & $0.075 \%$ & $0.042 \%$ \\
\hline Max & $2.137 \%$ & $2.065 \%$ & $1.608 \%$ & $2.086 \%$ \\
\hline Min & $-2.229 \%$ & $-2.241 \%$ & $-2.694 \%$ & $-2.271 \%$ \\
\hline Standard Deviation & $0.951 \%$ & $0.992 \%$ & $0.885 \%$ & $1.000 \%$ \\
\hline $\begin{array}{l}\text { Risk-adjusted return } \\
\text { (mean-SD ratio) }\end{array}$ & 0.047 & 0.037 & 0.098 & 0.064 \\
\hline TVC-GARCH(1,1) (TVC) & Hedged & Unhedged & EW-TFX & TFX \\
\hline Average weekly return* & $0.055 \%$ & $0.041 \%$ & $0.103 \%$ & $0.092 \%$ \\
\hline Median return & $0.034 \%$ & $0.085 \%$ & $0.291 \%$ & $0.130 \%$ \\
\hline Max return & $2.053 \%$ & $1.954 \%$ & $1.790 \%$ & $1.907 \%$ \\
\hline Min return & $-2.216 \%$ & $-2.471 \%$ & $-2.459 \%$ & $-2.289 \%$ \\
\hline Standard Deviation & $0.989 \%$ & $0.993 \%$ & $0.919 \%$ & $1.036 \%$ \\
\hline $\begin{array}{l}\text { Risk-adjusted return } \\
\text { (mean-SD ratio) }\end{array}$ & 0.056 & 0.041 & 0.112 & 0.089 \\
\hline
\end{tabular}

Note: MV, CC and TVC are the allocation schemes. TVC is Multivariate Time-varying Correlation GARCH model based on Cholesky Decomposition while CC is based on Constant correlation Multivariate GARCH model. Hedged, Unhedged, EW-TFX and TFX portfolios are allocation outcomes based on different currency management styles respectively. Hedged portfolios are based purely on using forward contracts, while unhedged portfolios are based purely on using spot rates. EW-TFX and TFX portfolios outcomes are based on the conditional hedging criterion. The portfolio outcome of TFX uses the three individual moving averages of 32, 61 and 117 days to determine hedging needs. The portfolio outcome of EW-TFX uses equally-weighted value of the three moving average days of 32, 61 and 117 to determine hedging needs. Section 3.1 discusses the use of the 32, 61 and 117 moving average days within the hedging criterion. The average returns are not significantly different from zero. However, there are some significant differences within the subsamples in different periods for some currencies portfolios. See table 4 for more details.

* This is the average weekly return over the one year period in 2010. 
portfolios. The EW-TFX portfolios' standard deviations are also slightly lower than other currencies portfolios in each allocation scheme. This confirms the argument in the literature that the EW-TFX is better in reducing volatility than the TFX portfolio. Taking the TVCGARCH (TVC) allocation scheme as an example, we see that the average weekly and median returns which are $0.103 \%$ and $0.291 \%$ respectively are better than the other currencies portfolios. The median return, for example, is 8.6 times better than the hedged currencies portfolio, 3.4 times better than the unhedged currencies portfolio and about 2 times better than the TFX overlay portfolio. The standard deviations (SD) of the various currencies portfolios differ only slightly, ranges from $0.919 \%$ (EW-TFX) to $1.036 \%$ (TFX).

However, the two currencies overlay portfolios do not appear able to cut losses as well as that of the hedged currencies portfolios. This is the same in all the allocation schemes. Both the EW-TFX overlay and the TFX overlay portfolios show a minimum return of $2.459 \%$ and $-2.289 \%$ respectively, which are slightly lower when compared to the minimum return of $-2.215 \%$ of the hedged currencies portfolio. It is also observed in table 2 that the ratio of mean to SD (0.112) is the highest for the EW-TFX overlay portfolio under the TVCGARCH $(1,1)$ scheme. When compared the risk adjusted returns within each allocation scheme, the EW-TFX overlay portfolio is always better.

I next evaluate the effects of correlation and allocated weights on currencies portfolio performances. The CC and the TVC schemes produce different portfolio outcomes due to the modelling of correlations underlying each scheme. Figures 1 and 2 show the correlations of the different currencies portfolios. Compare to figure 2, which reports the variation of weights for the three currencies in the estimation periods, it shows that JPY has a higher 
Figure 2A: Correlation patterns of JPY-GBP, JPY-EUR and GBP-EUR throughout the estimation periods

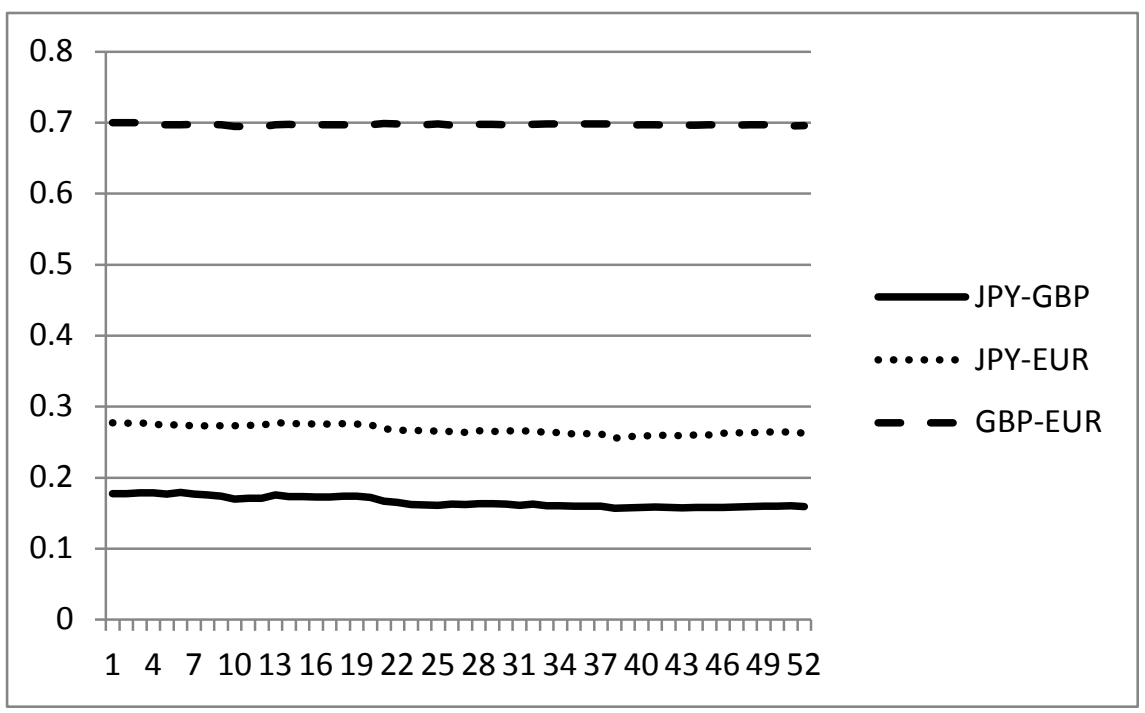

CC-EWTFX portfolio

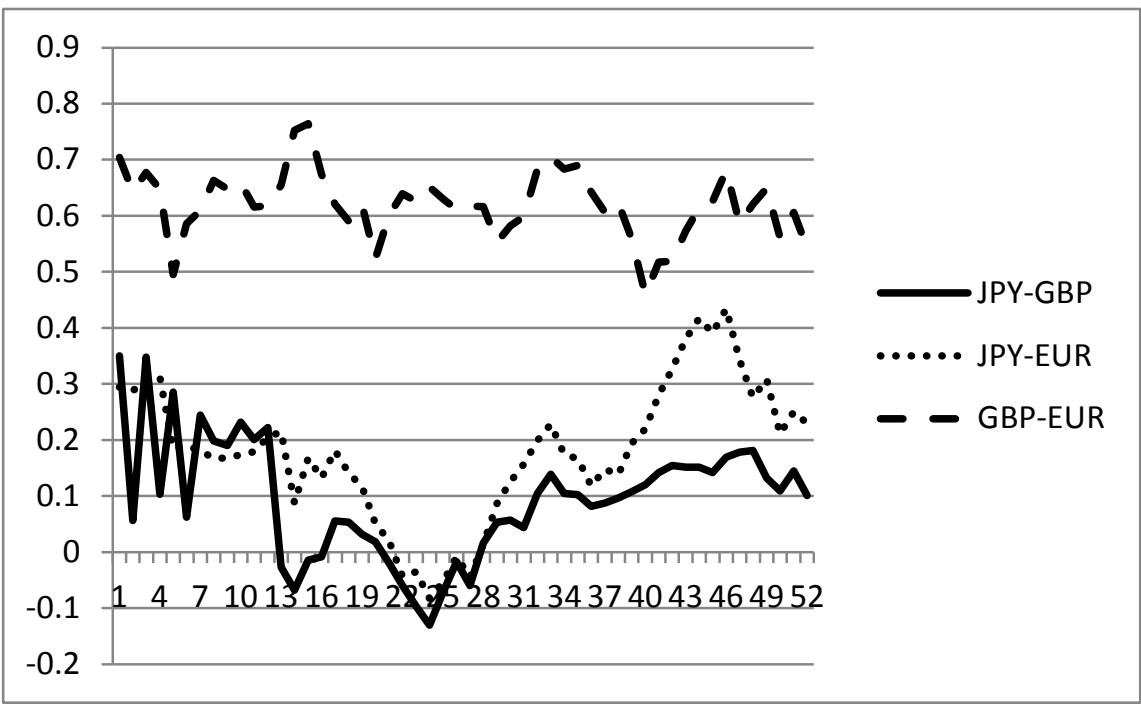

TVC-EWTFX portfolio

Note: The correlations of the above two figures are based on (i) CC-EWTFX and (ii) TVC-EWTFX portfolios. TVC is Multivariate Time-varying Correlation GARCH model based on Cholesky Decomposition while CC is based on Constant correlation Multivariate GARCH model. Both are used to model the variance covariance matrix in the currency overlay portfolio optimisations process, which is the equally weighted (EW) TFX portfolio in this case. These are the in-sample correlations underlying currencies pairs within the portfolios where the weights are derived. These weights are derived in sample using the recursive window approach, where the initial estimation dates are fixed at the first week of January of 1999 until the last week of December in 2009 to derive weights to allocate currencies to form portfolios in the one-week ahead period for January 2010 and additional observations are added one at a time to the estimation period with the last estimation dates from the first week of January 1999 until the third week of December in 2010, in order to derive weights to form portfolios out sample for December 2010. Figure 1A lists out graphically the in sample correlations of currencies pairs in the optimisation for determining weights for week 1 of 2010 until week 52 of 2010. 
Figure 2B: Correlation patterns of JPY-GBP, JPY-EUR and GBP-EUR throughout the estimation periods

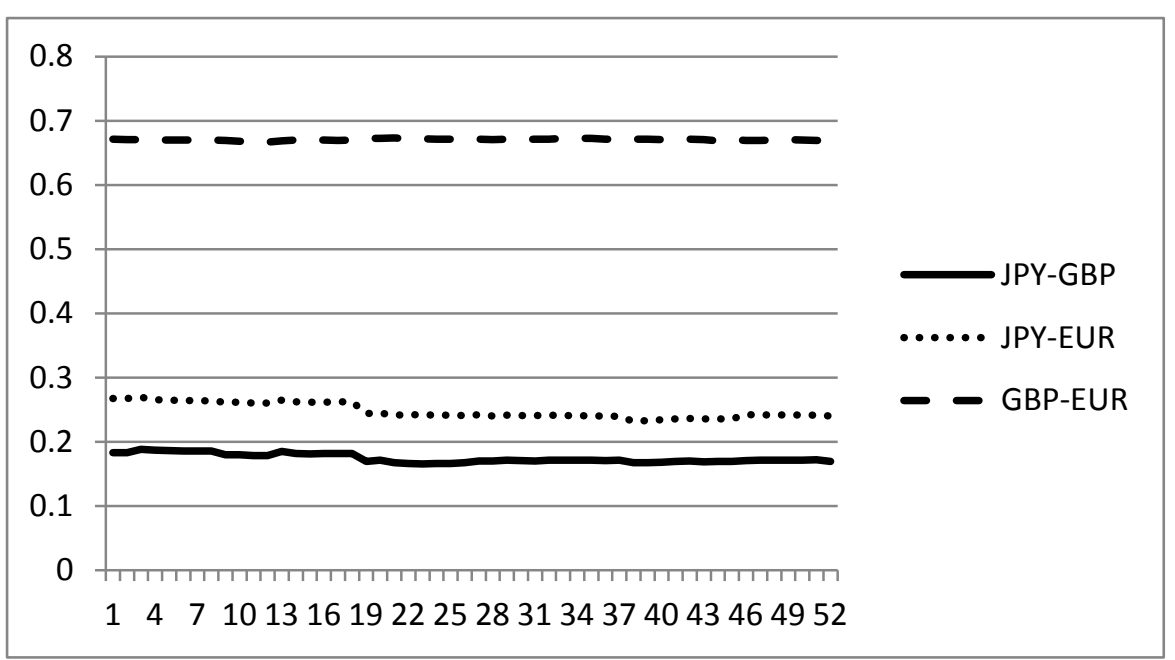

CC-TFX portfolio

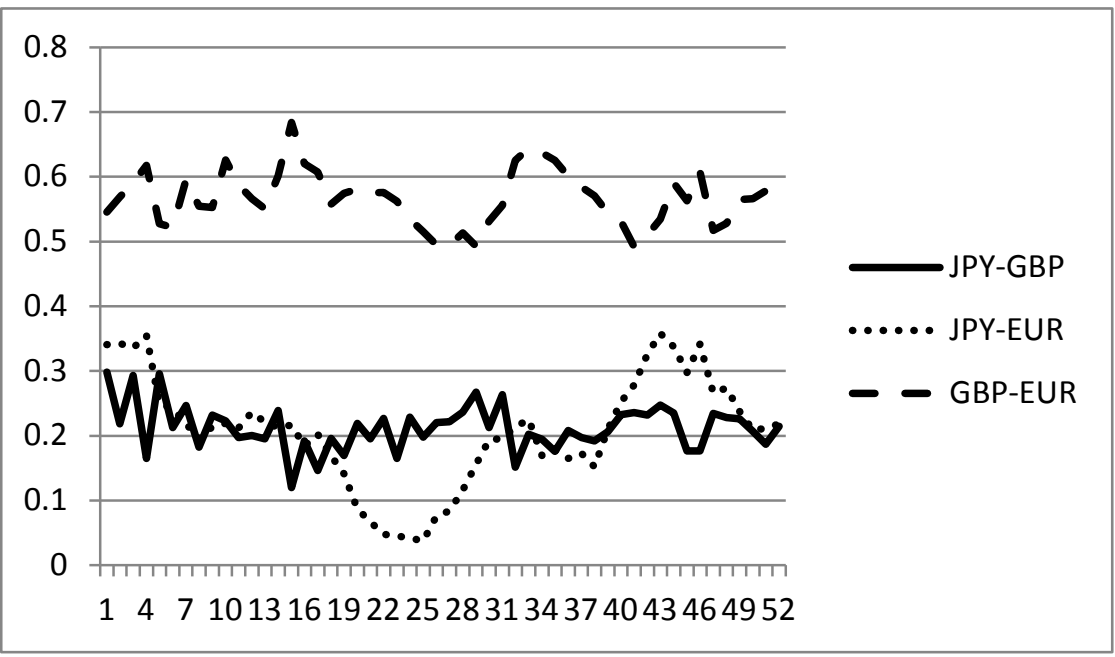

TVC-TFX portfolio

Note: The correlations of the above two figures are based on (i) CC-EWTFX and (ii) TVC-EWTFX portfolios. TVC is Multivariate Time-varying Correlation GARCH model based on Cholesky Decomposition while CC is based on Constant correlation Multivariate GARCH model. Both are used to model the variance covariance matrix in the currency overlay portfolio optimisations process, which is the TFX portfolio in this case. These are the in-sample correlations underlying currencies pairs within the portfolios where the weights are derived. These weights are derived in sample using the recursive window approach, where the initial estimation dates are fixed at the first week of January of 1999 until the last week of December in 2009 to derive weights to allocate currencies to form portfolios in the one-week ahead period for January 2010 and additional observations are added one at a time to the estimation period with the last estimation dates from the first week of January 1999 until the third week of December in 2010, in order to derive weights to form portfolios out sample for December 2010. Figure 1B lists out graphically the in sample correlations of currencies pairs in the optimisation for determining weights for week 1 of 2010 until week 52 of 2010. 


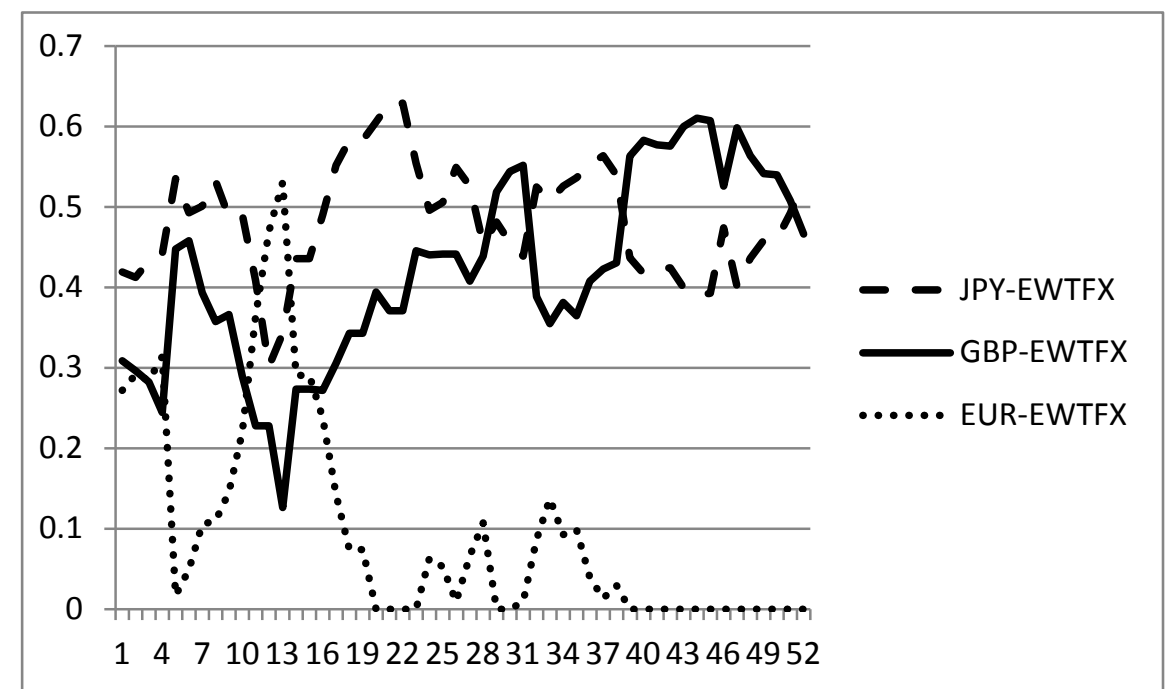

\section{CC-EWTFX portfolio}

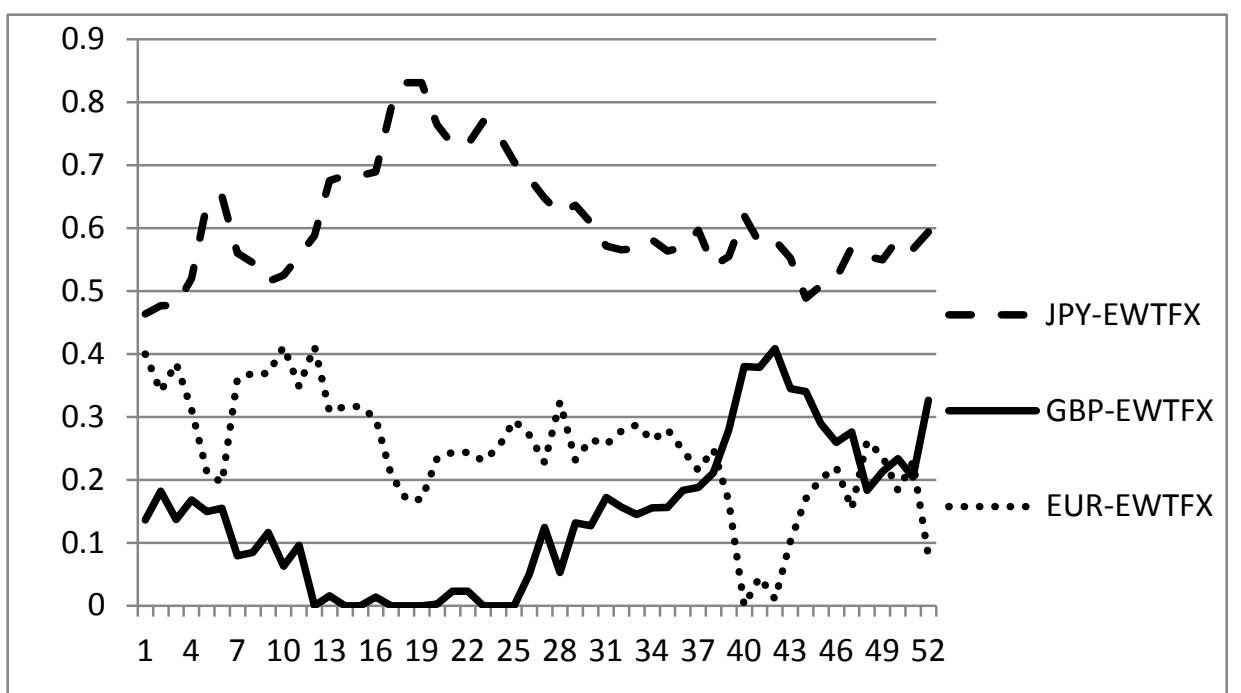

TVC-EWTFX portfolio

Note: The weights of the three currencies pairs, JPY, GBP and EUR reported in this figure are based on those formed under the (i) CC-EWTFX and (ii) TVC-EWTFX portfolios. TVC is Multivariate Time-varying Correlation GARCH model based on Cholesky Decomposition while CC is based on Constant correlation Multivariate GARCH model. Both are used to model the variance covariance matrix in the currency overlay portfolio optimisations process, which is the equally weighted (EW) TFX portfolio in this case. The optimal weights of the three currencies pairs are derived in sample using the recursive window approach, where the initial estimation dates are fixed at the first week of January of 1999 until the last week of December in 2009. The derived weights are then used for allocating the three currencies pairs out sample in the one-week ahead period for January 2010 to form the currency overlay portfolio. Then additional observations are added one at a time to the estimation period with the last estimation dates from the first week of January 1999 until the third week of December in 2010, in order to derive weights to form portfolios out sample for December 2010. Figure 2A lists out graphically the in sample weights of the three currencies pairs derived in the optimisation process for use in week 1 of 2010 until week 52 of 2010. 
Figure 3B: Patterns of the allocated weights of currencies in the overlay portfolios throughout the estimation periods

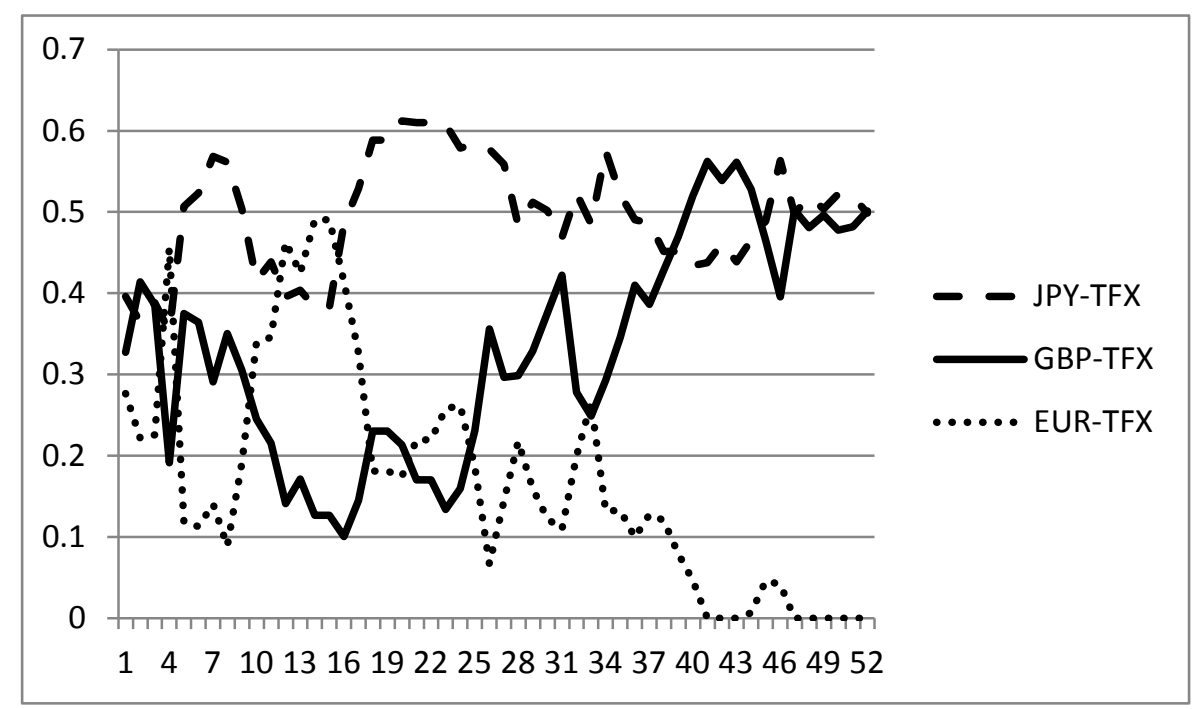

CC-TFX portfolio

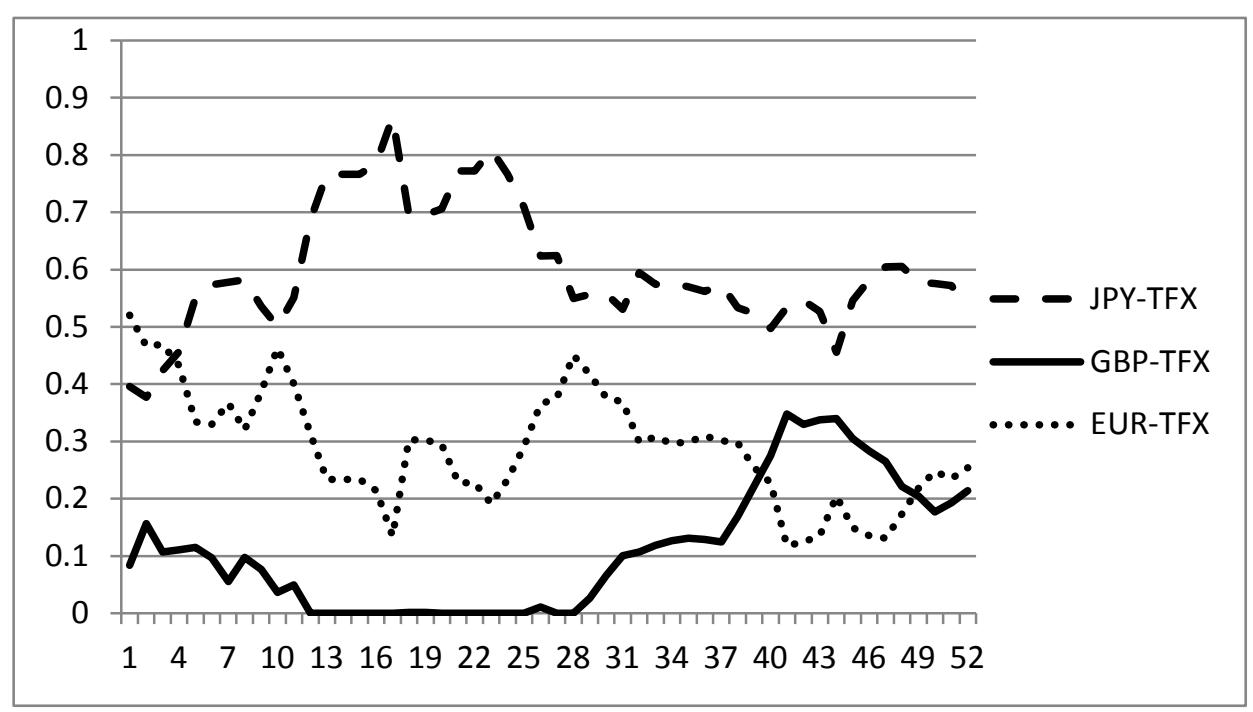

TVC-TFX portfolio

Note: The weights of the three currencies pairs, JPY, GBP and EUR reported in this figure are based on those formed under the (i) CC-TFX and (ii) TVC-TFX portfolios. TVC is Multivariate Time-varying Correlation GARCH model based on Cholesky Decomposition while CC is based on Constant correlation Multivariate GARCH model. Both are used to model the variance covariance matrix in the currency overlay portfolio optimisations process, which is the TFX portfolio in this case. The optimal weights of the three currencies pairs are derived in sample using the recursive window approach, where the initial estimation dates are fixed at the first week of January of 1999 until the last week of December in 2009. The derived weights are then used for allocating the three currencies pairs out sample in the one-week ahead period for January 2010 to form the currency overlay portfolio. Then additional observations are added one at a time to the estimation period with the last estimation dates from the first week of January 1999 until the third week of December in 2010, in order to derive weights to form portfolios out sample for December 2010. Figure 2A lists out graphically the in sample weights of the three currencies pairs derived in the optimisation process for use in week 1 of 2010 until week 52 of 2010. 
proportion when allocated by the TVC rather than the CC scheme ${ }^{8}$, which is supported by the relatively lower (negative) correlations of JPY with EUR and with GBP shown in figure 1. This also supports the diversification of the EW-TFX currencies strategy to some extent, as the EW-TFX currencies overlay portfolios, under the TVC scheme produce better for the weekly, median and risk-adjusted returns. This findings support existing evidence in Acar and Lequeux (2001) that show equally weighted moving average FX strategy in overlay portfolios could lead to better risk reduction.

\section{2: Significance of the outperformance of the currencies portfolios}

This section discusses the statistical significance differences between currencies portfolios within and across the allocation schemes. I test them by comparing the sub-samples on quarterly and monthly bases. The significantly different currencies portfolios are listed in table 3. The result shows that significant differences between portfolio returns are stronger across allocation schemes than within each allocation scheme. The CC scheme shows some significant differences in the sub-sample, implying some impacts from managing the currency exposure differently. On the other hand, there are also some significant differences between sub-samples on monthly and quarterly bases for individual currencies portfolios under each allocation scheme as shown in table 4.

\footnotetext{
${ }^{8}$ Some periods have zero allocations for certain currencies as seen in the figures. This is possible as it is sometimes permissible to have zero allocations to the currency pairs' assets for currency overlay program professionally. For example, the currency overlay program for the California Public Employees' Retirement Plan allows such allocation scheme. See http://www.calpers.ca.gov/eip-docs/investments/policies/inv-asset-classes/fixed-income/currency-overlay.pdf
} 
Table 3: Significantly different currencies portfolios within and across allocation schemes

\section{A) Within allocation schemes}

\begin{tabular}{|c|c|c|c|}
\hline & Markowitz (MV) & CC-GARCH $(1,1)(C C)^{*}$ & TVC-GARCH(1,1) (TVC)* \\
\hline $\begin{array}{l}\text { monthly } \\
\text { sub sample }\end{array}$ & nil & $\begin{array}{c}\text { un \& hed (M1) } \\
(-0.0698 \% \text { \& } 0.1168 \%) \\
\text { tf \& hed (M10) } \\
(0.4924 \% \text { \& } 0.4669 \%) \\
\text { tf \& ew (M11) } \\
(-0.5656 \% \text { \& }-0.1851 \%) \\
\text { ew \& uh (M11) } \\
(-0.1851 \&-0.6387 \%) \\
\text { nil }\end{array}$ & $\begin{array}{c}\text { ew \& hed (M6) } \\
(0.0801 \% \text { \& } 0.3533 \%)\end{array}$ \\
\hline
\end{tabular}

B) Across allocation schemes

\begin{tabular}{|c|c|c|}
\hline quarter \& month period & portfolios comparison pair & corresponding portfolios' returns in pair* \\
\hline Q1 to Q3 & nil & nil \\
\hline Q4 & tvctf \& mvhed & $0.0605 \% \&-0.0277 \%$ \\
\hline M1 & $\begin{array}{l}\text { tvcuh \& mvhed } \\
\text { ccuh \& mvhed } \\
\text { mvtf \& ccuh }\end{array}$ & $\begin{array}{c}0.0599 \% \text { \& } 0.2857 \% \\
-0.0698 \% \text { \& } 0.2857 \% \\
0.265 \% \text { \& }-0.0698 \%\end{array}$ \\
\hline M2 & tvctf \& mvuh & $-0.2646 \% \&-0.6108 \%$ \\
\hline M3 & nil & nil \\
\hline M4 & $\begin{array}{l}\text { cched \& tvched** } \\
\text { mvtf \& tvched** } \\
\text { mvuh \& cched** } \\
\text { mvtf \& cched** } \\
\text { tvcew \& mvhed } \\
\text { mvew \& tvcew }\end{array}$ & $\begin{array}{c}-0.0826 \% \text { \& }-0.1896 \% \\
0.1483 \% \text { \& }-0.1896 \% \\
0.1553 \% \text { \& }-0.0826 \% \\
0.1483 \% \&-0.0826 \% \\
-0.3078 \% \& 0.0409 \% \\
0.0163 \% \&-0.3078 \%\end{array}$ \\
\hline M5 & $\begin{array}{l}\text { tvcew \& mvuh } \\
\text { ccew \& tvcew } \\
\text { mvew \& tvcew } \\
\text { mvew \& ccew }\end{array}$ & $\begin{array}{c}0.4137 \% \text { \& }-0.4559 \% \\
0.0469 \% \text { \& } 0.4137 \% \\
-0.3964 \% \text { \& } 0.4137 \% \\
-0.3964 \% \& 0.0469 \%\end{array}$ \\
\hline
\end{tabular}


Table 3: Significantly different currencies portfolios within and across allocation schemes (con't)

\begin{tabular}{|c|c|c|}
\hline quarter \& month period & portfolios comparison pair & corresponding portfolios' returns in pair* \\
\hline \multirow{7}{*}{ M6 } & tvcew \& cched & $0.0801 \%$ \& $0.5212 \%$ \\
\hline & tvcew \& mvhed & $0.0801 \%$ \& $0.5393 \%$ \\
\hline & tvcew \& ccuh & $0.0801 \%$ \& $0.4296 \%$ \\
\hline & mvtf \& ccuh & $0.4539 \%$ \& $0.4296 \%$ \\
\hline & tvcew \& mvuh & $0.0801 \% \& 0.451 \%$ \\
\hline & cctf \& tvcew & $0.3780 \% \&$ \& $0.0801 \%$ \\
\hline & mvtf \& tvcew & $0.4539 \%$ \& $0.0801 \%$ \\
\hline M7 & tvcuh \& mvhed & $0.8673 \%$ \& $0.7393 \%$ \\
\hline \multirow[t]{5}{*}{ M8 } & mvhed \& tvched & $0.2109 \%$ \& $0.1579 \%$ \\
\hline & mvtf \& cched & $0.1823 \% \& 0.2809 \%$ \\
\hline & ccuh \& tvcuh & $0.2452 \% \& 0.0983 \%$ \\
\hline & cctf \& tvcuh & $0.2536 \% \& 0.0983 \%$ \\
\hline & mvew \& ccew & $0.1713 \% \& 0.3009 \%$ \\
\hline M9 & Nil & Nil \\
\hline M10 & tvctf \& mvhed & $0.6027 \%$ \& $0.5399 \%$ \\
\hline \multirow[t]{3}{*}{ M11 } & ccuh \& tvcuh & $-0.6387 \%$ \& $-0.5871 \%$ \\
\hline & mvew \& ccuh & $-0.2958 \%$ \& $-0.6387 \%$ \\
\hline & mvew \& ccew & $-0.2958 \% \&-0.1851 \%$ \\
\hline M12 & tvctf \& mvhed & $0.1603 \% \&-0.0078 \%$ \\
\hline
\end{tabular}

Note: Table 3 lists the currencies portfolios pairs that are significantly different from each other, in terms of the sub-samples based on the month and quarter periods. Panel A lists those within the same allocation. Panel B lists those across different allocation schemes. M1 denotes the month of January, until M12 denoting the month of December. Q1 denoting the first quarter until Q4 denoting the fourth quarter. Panel A places the period of the subsample in bracket next to the portfolios pairs. Panel B lists the subsample period in the first column. For the currencies portfolios pairs, the first two or three letters denote "allocation schemes" and these are tvc (TVC-GARCH(1,1)), cc (CC-GARCH(1,1)) and mv (Markowitz) and the next two or three letters denote currencies portfolios, and these are uh (unhedged), hed (hedged), ew (EW-TFX) and tf (TFX). All currencies portfolio pairs reported are significantly different from each other at $10 \%$ level, and those with ** are significant at $5 \%$ level. The Wilcoxon Signed Rank test has been used to conduct the statistical significant test due to the small number of data in each sub sample.

* Panel A lists the average weekly returns of the corresponding portfolios pairs based on the particular quarter or month of the year in bracket below the portfolios pairs. Panel B list them in the third column. 


\begin{tabular}{llllll}
\hline \multicolumn{3}{l}{ Markowitz (MV) } & \multicolumn{3}{l}{} \\
\hline \multirow{5}{*}{ Hedged } & M6/M2, & M9/M2, & M4/M3, & M6/M5, & M7/M5, \\
& M12/M6, & M11/M7, & M11/M10 & & \\
Un-hedged & M6/M2, & M9/M2, & M10/M2, & M4/M3, & M7/M3, \\
& M7/M4, & M12/M6, & M11/M8 & Q3/Q & \\
& & & & & \\
EW-TFX & M2/M1, & M12/M1, & M4/M2, & M6/M2, & M7/M2, \\
& M8/M2, & M9/M2, & M6/M5, & M7/M5, & M9/M5, \\
& M12/M7, & M11/M8, & Q3/Q1, & Q4/Q3 & \\
TFX & & & & & \\
& M2/M1, & M6/M2, & M9/M2, & M10/M2, & M12/M2, \\
& M4/M3, & M7/M3, & M7/M4, & M8/M5, & M12/M6, \\
& M11/M7, & M11/M10, & Q3/Q1, & Q3/Q2 &
\end{tabular}

\begin{tabular}{llllll}
\hline CC-GARCH(1,1) (CC) & & & & \\
\hline \multirow{2}{*}{ Hedged } & M6/M2, & M9/M2, & M4/M3, & M7/M4, & M12/M6, \\
& M11/M8, & Q3/Q1 & & \\
\multirow{2}{*}{ Un-hedged } & M9/M2, & M7/M3, & M7/M4**, & M11/M8 & Q3/Q1, \\
& Q3/Q2 & & & \\
EW-TFX & M7/M1, & M12/M1, & M5/M2, & M6/M2, & M7/M2, \\
& M8/M2, & M4/M3, & M11/M8, & Q3/Q1** & \\
& & & & \\
TFX & M9/M2, & M7/M3, & M7/M4**, & M7/M5, & M11/M7, \\
& M11/M8, & M11/M10, & Q3/Q1**, & Q3/Q2. & \\
& & & & \\
\end{tabular}


Table 4: Significantly different monthly and quarterly sub samples in the currencies portfolios (con't)

\begin{tabular}{|c|c|c|c|c|c|}
\hline \multicolumn{6}{|c|}{ TVC-GARCH(1,1) (CC) } \\
\hline Hedged & $\begin{array}{l}\text { M9/M2, } \\
\text { Q3Q1, }\end{array}$ & $\begin{array}{l}\text { M12/M2, } \\
\text { Q3/Q2 }\end{array}$ & M4/M3, & $\mathrm{M} 7 / \mathrm{M} 4^{* *}$, & M8/M7, \\
\hline Un-hedged & M9/M2, & M4/M3, & M7/M4**, & M11/M7 & \\
\hline EW-TFX & $\begin{array}{l}\text { M7/M1, } \\
\text { M11/M8, }\end{array}$ & $\begin{array}{l}\text { M5/M2, } \\
\text { Q3/Q1** }\end{array}$ & M7/M2, & M9/M2, & M7/M4, \\
\hline TFX & $\begin{array}{l}\text { M9/M2, } \\
\text { M11/M10, }\end{array}$ & $\begin{array}{l}\text { M7/M3, } \\
\text { Q3/Q1 }\end{array}$ & M7/M4, & M8/M7, & M11/M7, \\
\hline
\end{tabular}

Note: Table 4 reports the results of the statistical significant test for the differences of the sub samples within the 52 weekly currencies portfolio returns, namely Hedged, Un-hedged, EW-TFX and TFX portfolios, as listed in table 1. Table 4 use both quarterly and monthly based sub-samples. Quarterly based sub-samples consist of all individual weekly returns that made up one quarter while monthly based sub-samples consist of all individual weekly returns that made up one month. These subsamples are then compared with each other in pair either quarter with quarter or month with month. The results reported show significant differences of the sub samples within the 52 weekly returns, at $10 \%$ significant level, those with ** are significant at $5 \%$ based on the various sub-samples on a month or quarter basis. M1 indicates January and M2 indicates February and this goes on until December. Q1 indicates quarter one and this goes on until quarter four. The Wilcoxon Signed Rank test has been used to conduct the statistical significance test due to the small sub sample sizes. 
Table 3 reveals more evidences of currencies portfolios outperformances across different allocation schemes. This shows the stronger impact of allocation schemes than that of the risk exposure management strategies when comparing the sub-samples of the currencies portfolios month-by-month. However, the effectiveness of the type of currency risk management used appears not to be conclusive. For example, in the month of May 2010 (M5), the TVC scheme for EW-TFX (i.e., tvcew) portfolios' returns are significantly different to other currencies portfolios and that the average weekly returns of the EW-TFX overlay portfolio using the TVC schemes is $0.4137 \%$ and this is also higher than all other currencies portfolios for the month of May, showing evidence of outperformance. Turning to the month of June 2010 (M6), the reverse however is true. It shows the TVC scheme for EW-TFX portfolios only produces average weekly return of $0.0801 \%$, and no longer outperforms other portfolios.

\section{Conclusion}

This paper proposes an approach to optimally construct currency overlay portfolios. The approach uses the multivariate TVC GARCH and multivariate CC GARCH models as allocation schemes, with the underlying returns originated from a moving average-based trend following single FX strategy in a hedging criterion. For comparison, the paper includes the average values (equally weighted) from the combination of the three single (and different) moving average days to determine the hedging needs underlying the hedging criterion. This produces the EW-TFX and TFX returns that are then used to optimise and construct the currency overlay portfolios. 
Our findings reveal the EW-TFX portfolios adopting the TVC-GARCH scheme produce the best risk-adjusted returns, supporting existing evidence in Acar and Lequeux (2001) who show that the equally weighted moving average FX strategy in overlay portfolios to give better risk reduction. When tested for significant differences in the portfolios, those in the same allocation scheme do not show stronger significant differences based on the monthly and quarterly sub-samples, except for the CC-GARCH $(1,1)$ allocation scheme. There are, however, more of such evidences when comparing the portfolios' returns across allocation schemes, showing the stronger impact of the allocation schemes.

This paper makes a contribution by introducing optimisation in the process of constructing the currency overlay portfolios, an angle not been explored in the existing literature that often rely on pre-determined fixed weights to allocate currencies to form overlay portfolios and this may not always be optimal. Though appropriate, including the optimisation adds to the complexity in the process. To investigate the effect and implement this efficiently, this paper uses a three currencies' portfolio to conduct the empirical study. The main limitation of this approach is the smaller number of currencies used, which may have led to the outcomes of the statistical significance tests for the differences in the portfolios' returns across and within the allocation schemes. The portfolios' construction is fairly restrictive in the numbers of currencies that could be allocated to form portfolios and hence impact on the variability of returns period on period to the extent it affected the significant difference levels in the returns of the allocation schemes. Future research could use a relatively flexible Multivariate GARCH model capable of accommodating a larger numbers of currencies to enable a more efficient implementation in the process. 
Research on currency overlay management remains an area of interest from the professional and academic perspectives, following recent survey from the BIS that revealed increasingly more currency overlay professional trading in the FX markets. More importantly, recent volatility of the foreign exchange markets (in particular, the immediate period post Brexit) would also have prompted interest to effectively managing the FX exposure for international investors. Therefore, a few important areas could also be explored. This includes optimizing overlay portfolios based on the returns of the FX strategies that apply carry-trade, momentum and term-spread strategies, which was applied in Gyntelberg and Schrimpf (2012). This is also relevant as findings from Gyntelberg and Schrimpf (2012) showed that the overlay portfolios reveal substantial tail risks. Moreover, findings from Gyntelberg and Schrimpf's (2012) also reveal that the common equity benchmarks feature even have greater downside risks than the FX strategies. This further reveals the need to apply more effective currency overlay strategies, such as an integrative approach that aims at optimising both the exposure and volatility of the currency and the underlying asset markets, to appropriately incorporate the risk appetites of international investors. This should be the next important future research area.

\section{References}

Acar, E. and Lequeux, P. (2001). Pursuing the debate on active currency management. The Journal of Alternative Investment (spring), 9-28.

Asai, M., McAleer M., Yu, J. (2006). Multivariate Stochastic Volatility: A Review, Econometric Reviews 25(2-3),145-175. 
Bank for International Settlement (BIS). (2016). Triennial Central Bank Survey of Foreign Exchange and Derivatives Market Activity in 2016 - Final results, https://www.bis.org/publ/rpfx16.htm , accessed 7th September 2016

Bollerslev, T. (1990). Modelling the Coherence in Short-Run Nominal Exchange Rates: A Multivariate Generalized ARCH Model. Review of Economics and Statistics 72, 498-505.

Campbell, J. Y., K. S. de Medeiros, and L. M. Viceira (2010). Global Currency Hedging, Journal of Finance 65, 87-121.

Dunis, C.L. and Levy, N. (2002). Do exotic currencies improve the risk-adjusted performance of dynamic currency overlays? The Journal of Asset Management 2(4), 336-352.

Engle R. (2002). Dynamic conditional correlation a simple class of multivariate GARCH models. Journal of Business and Economic Statistics 20, 339-350.

Embrlchts, P., Mcneil, A. and Straumann, D. (1999). Correlation and dependence in risk management: Properties and pitfalls, Working Paper, Department of Mathematics, ETHZ, Zurich (July).

Gyntelberg, J and Schrimpf. (2012). Downside risk properties of foreign exchange and equity investment strategies, Journal of investment Strategies 1(2), p3-21.

Gallardo, P. and A. Heath, (2009). Execution Methods in Foreign Exchange Markets, Bank of International Settlements Quarterly Review, March, p83 - 91. 
Jondeau E, and Rockinger M. (2001). The copula-GARCH model of conditional dependencies: an international stock-market application. Journal of International Money and Finance 25, 827-853.

Joliffe, I. T. (1986). Principal Component Analysis, New York: Springer-Verlag.

Jorion, P. (1994). Mean-Variance Analysis of Currency Overlays, Financial Analysts Journal 50(3). 48-56

Kroencke, T. A., Schindler, F., Schrimpf, A., (2014). International diversification benefits with foreign exchange investment styles. Review of Finance 18, 1847-1883

LaBarge (2010). Currency management: Considerations for the equity hedging decision, Vanguard research, September.

Lindahl, U.J (1997). "Currency Overlay Management." AIMA Newsletter, April.

Mardia, K., (1970). Measures of multivariate skewness and kurtosis with applications. Biometrika 57, 519-530.

Markowitz HM. (1952). Portfolio selection. The Journal of Finance 7, 77-91.

Mahalanobis, P. C. (1936). On the generalised distance in statistic. In: Proceedings of the National Institute of Sciences of India. 
Middleton, A. (2005). Trading Style Analysis: A Quantitative Assessment of the Currency Industry. The Journal of Alternative Investment, 14-28.

Nasypbek, S. and Rehnam, S, S. (2011). Explaining the returns of active currency managers, Bank for international Settlement Working Paper No. 58.

Pourahmadi M. 1999, Joint mean-covariance models with applications to longitudinal data: Unconstrained parameterisation. Biometrika 86, p677-690.

Pojarliev, M., (2005). Performance of Currency Trading Strategies in Developed and Emerging Markets: Some Striking Differences, Financial Markets and Portfolio Management 19(3), 297 - 311.

Pojarliev, M., and R. M. Levich (2012). Is There Skill or Alpha in Currency Investing? In: The Handbook of Exchange Rates, Jessica James, Ian March and Lucio Sarno (eds.) Wiley.

Solnik, B. (1997). Integrating Global Asset Allocation and Currency Management. AIMR Conference Proceedings: Managing Currency Risk (November): 60-70.

Sweeting, P., (2010). Financial Enterprise Risk Management. Cambridge University Press Tee, K-H., (2009). Is active currency management effective for international equity portfolios involving managed futures and hedge funds? Journal of Derivatives \& Hedge Funds 15, 137148 
Tsay RS.(2005). Analysis of Financial Time Series. John Wiley: New York

\section{Appendix 1}

To apply Cholesky Decomposition, the variance-covariance matrix, $\sum_{t}$ is assumed to be characterised with positive definite. This follows a lower triangular matrix $\boldsymbol{L}_{\boldsymbol{t}}$ to exist with unit diagonal elements and a diagonal matrix $\boldsymbol{G}_{\boldsymbol{t}}$ with positive diagonal elements such that

$\sum_{t}=\boldsymbol{L}_{t} \boldsymbol{G}_{t} \boldsymbol{L}_{t}^{\prime}$

where $\boldsymbol{L}_{\boldsymbol{t}}=\left[\begin{array}{ccc}1 & 0 & 0 \\ q_{21, t} & 1 & 0 \\ q_{31, t} & q_{32, t} & 1\end{array}\right], \quad \boldsymbol{G}_{\boldsymbol{t}}=\left[\begin{array}{ccc}\mathrm{g}_{11, \mathrm{t}} & 0 & 0 \\ 0 & \mathrm{~g}_{22, \mathrm{t}} & 0 \\ 0 & 0 & \mathrm{~g}_{33, \mathrm{t}}\end{array}\right]$

Therefore, $\left.\Sigma_{t}=\mid \begin{array}{lll}\sigma_{11, t} & \sigma_{21, t} & \sigma_{31, t} \\ \sigma_{21, t} & \sigma_{22, t} & \sigma_{32, t} \\ \sigma_{31, t} & \sigma_{32, t} & \sigma_{33, t}\end{array}\right\rfloor$

$=\left[\begin{array}{ccc}\mathrm{g}_{11, t} & q_{21, t} \mathrm{~g}_{11, t} & q_{31, t} \mathrm{~g}_{11, t} \\ q_{21, t} \mathrm{~g}_{11, t} & q_{21, t}^{2} \mathrm{~g}_{11, t}+\mathrm{g}_{22, t} & q_{31, t} q_{21, t} \mathrm{~g}_{11, t}+q_{32, t} \mathrm{~g}_{22, t} \\ q_{31, t} \mathrm{~g}_{11, t} & q_{31, t} q_{21, t} \mathrm{~g}_{11, t}+q_{32, t} \mathrm{~g}_{22, t} & q_{31, t}^{2} \mathrm{~g}_{11, t}+q_{32, t}^{2} \mathrm{~g}_{22, t}+\mathrm{g}_{33, t}\end{array}\right]$

The above conditional variance $\left(\sigma_{11, t}, \sigma_{22, t}\right.$ and $\left.\sigma_{33, t}\right)$ and the conditional covariance functions $\left(\sigma_{21, t}, \sigma_{31, t}\right.$ and $\left.\sigma_{32, t}\right)$ are re-parameterised under Cholesky Decomposition and now include the parameters of $\mathrm{g}_{i j}$ (for $i=j$ ) and $q_{i j}$ (for $i>j$ ). The above illustrates the decomposition for a 3-asset portfolio, which is the case in this paper. As the number of assets 
increase, the decomposition involves more processes. Tsay (2005) defines the general ndimensional cases for the conditional variance $\left(\sigma_{i i, t}\right)$ and covariance $\left(\sigma_{i j, t}\right)$ as follows:

$$
\begin{gathered}
\sigma_{i i, t}=\operatorname{Var}\left(a_{i t} \mid \boldsymbol{F}_{t-1}\right)=\sum_{v=1}^{i} q_{i v, t}^{2} \mathrm{~g}_{v v, t}, \quad i=1, \ldots \ldots, k, \\
\sigma_{i j, t}=\operatorname{Cov}\left(a_{i t}, a_{j t} \mid \boldsymbol{F}_{t-1}\right)=\sum_{v=1}^{j} q_{i v, t} q_{j v, t} \mathrm{~g}_{v v, t}, \quad j<i \quad i=2, \ldots, k
\end{gathered}
$$

where $q_{v v, 1}=1$ for $v=1, \ldots, k$.

\section{Appendix 2}

This appendix discusses the derivation of the Mardia's tests for multivariate normality adapted from Sweeting (2010). Numerical tests based on measures of multivariate (bivariate) skew and kurtosis (Mardia's test) are derived to test multivariate normality of data sets or data pairs. Tests are normally carried out jointly based on Mahalanobis (1936), using the Mahalanobis distance and the Mahalanobis angle. Mahalanobis distance deals with outliers within datasets by identifying observations that lie far away from the centre of the data cloud, giving less weight to variables with large variances or to groups of highly correlated variables (Joliffe (1986)). We discuss the computation of the Mahalanobis distance as follows:

Consider the column vector $X_{t}$ which contains the observations at time $t$ where $t=$ $1,2, \ldots, T$ for a group of $N$ variables, so $X_{t}^{\prime}=\left(X_{1, t}, X_{2, t}, \ldots . X_{N, t}\right)$. Let the column vector $\bar{X}$ contain the sample mean for each variable calculated over all $t=1,2, \ldots, T$ so $\bar{X}_{t}^{\prime}=\left(\bar{X}_{1}\right.$, 
$\left.\bar{X}_{2}, \ldots, \bar{X}_{N}\right)$. Then, let $S$ be an $N \times N$ matrix of the sample covariances of the $N$ variables based on the observations from $t=1,2, \ldots, T$ :

$\left[\begin{array}{cccc}S_{X_{1} X_{1}} & S_{X_{1} X_{2}} \ldots \ldots & S_{X_{1} X_{N}} \\ S_{X_{2} X_{1}} & S_{X_{2} X_{2}} \ldots \ldots & S_{X_{2} X_{N}} \\ \vdots & \vdots & & \vdots \\ S_{X_{N} X_{1}} & S_{X_{N} X_{2}} \ldots \ldots & S_{X_{N} X_{N}}\end{array}\right]$

Where $S_{X_{n}, X_{m}}$ is the sample covariance between the observations for variables $m$ and $n$ calculated over all $i=1,2, \ldots, T$, and where $S_{X_{n}, X_{m}}=S_{X_{n}}^{2}$, the variance of the observations for variable $n$. The Mahalanobis distance at time $t, D_{t}$ is then calculated as:

$D_{t}=\sqrt{\left(X_{t}-\bar{X}\right)^{\prime} S^{-1}\left(X_{t}-\bar{X}\right)}$

Squaring the Mahalanobis distance gives the statistics that is the sum of $N$ normal variables, assuming variables are drawn from a multivariate normal distribution. The statistic $D_{t}^{2}$ has a $\chi^{2}$ distribution with $N$ degrees of freedom. Deriving the numerical tests based on measures of multivariate skew and kurtosis (Mardia (1970)), involves defining the Mahalanobis angle between observations at times $s$ and $t, D_{s, t}$ :

$D_{s, t}=\left(X_{t}-\bar{X}\right)^{\prime} S^{-1}\left(X_{t}-\bar{X}\right)$

Following that, a skew-type parameter, $W_{N}$ can be calculated:

$W_{N}=\frac{1}{T^{2}} \sum_{s=1}^{T} \sum_{t=1}^{T} D_{s, t}^{3}$ 
Multiplying this by $T / 6$ gives Mardia’s skew and statistic, $M S T$, that has a $\chi^{2}$ distribution with $N(N+1)(N+2) / 6$ degrees of freedom, which will be the case under the null hypothesis where it will be a standard normal

$M S T=\frac{T}{6} W_{N} \sim X_{N(N+1)(N+2) / 6}^{2}$

For Mardia's test of multivariate kurtosis, the kurtosis-type parameter, $K_{N}$, is, however, calculated from the Mahalanobis distance:

$K_{N}=\frac{1}{T} \sum_{i=1}^{T} D_{t}^{4}$

This can be transformed into Mardia’s Kurtosis test statistic, $M K T$, which tends to a standard normal distribution as $T$ tends to infinity:

$M K T=\frac{K_{N} \sim N(N+2)}{\sqrt{8 N(N+2) / T}} \sim N(0,1)$

I model conditional mean equations based on AR(1) to generate residual series of JPY, EURO and the GBP, all in US Dollar terms. These are used to compute the Multivariate Time-varying (TVC)-GARCH and the Constant Correlation (CC)-GARCH models. I test for bivariate normality for the currencies in each estimation period for these two models, involving JPY \& EURO, JPY \& GBP and EURO \& GBP, based on the Mardia’s test involving multivariate skewness (MST) and multivariate kurtosis (MKT) as above derived. 
There are two sets of tests in each estimation period with the first estimation starting from the first week of 1990 until the last week in 2009 and the last estimation from the first week of 1990 to the third week of 2010 in December.

The null hypothesis of bivariate normality are rejected for the two sets of tests in each of these periods, confirming that correlation coefficients of the currencies' pairs may be biased to reveal the precise interdependence pattern, where the consistent relationship throughout may be affected underlying their joint distributions. 